\title{
ĐÁNH GIÁ THỰC TRẠNG KẾT QUẢ THAM GIA THỬ NGHIỆM THÀNH THẠO CÁC CHƯO'NG TRINH HÓA LÝ NĂM 2017
}

\author{
${ }^{1}$ Đặng Hũu Cưò̀ng \\ Viện Kiểm nghiệm an toàn vệ sinh thực phẩm Quốc gia
}

(Ngày đến tòa soạn: 4/6/2018; Ngày sỉa bài sau phản biện: 12/7/2018; Ngày chấp nhận đăng: 24/7/2018)

\section{Tóm tắt}

THỬ nghiệm thành thạo đóng một vai trò rất quan trọng trong việc đảm bảo chất luợng của kết 1 quả thư nghiệm. Dựa trên kết quả thư nghiệm thành thạo, các nhà quản lý cũng nhu các đơn vị liên quan sẽ đánh giá được năng lục của phòng thí nghiệm. Việc tham gia thử nghiệm thành thạo cũng là bằng chứng cho thấy phòng thi nghiệm đang thực hiện qui trình quản lý chất lượng theo tiêu chuẩn ISO/IEC17025 để nâng cao chất lượng kiểm nghiệm trong cả nước. Thông qua chương trình thử nghiệm thành thạo, các đơn vị tụ đánh giá năng lực của mình và đồng thời tìm ra nguyên nhân ảnh huởng đến chất lương của kết quả kiểm nghiệm để có biện pháp cải tiến, khắc phục và chinh xác kết quả để đảm bảo chất lương tốt hơn.

Bài báo này sẽ đưa ra một bức tranh tổng thể về năng lực kiểm nghiệm của các phòng thí nghiệm kiểm nghiệm thực phẩm trong và ngoài ngành y tế dựa trên kết quả tham gia thử nghiệm thành thạo do Viện Kiểm nghiệm an toàn vệ sinh thực phẩm Quốc gia (NIFC) tổ chức trong năm 2017.

\section{I. ĐẠTT VẤN Đî̀}

Thử nghiệm thành thạo (TNTT) là một trong những công cụ quan trọng giúp các đơn vị tự xem xét, đánh giá năng lực, độ chính xác các kết quả phân tích, đồng thời đánh giá kỹ năng và tay nghề của kiểm nghiệm viên. Hiện nay, các yêu cầu và chính sách của các đơn vị công nhận như BoA, A2LA, ILAC thì việc tham gia thử nghiệm thành thạo hay so sánh liên phòng là một yêu cầu bắt buộc để đánh giá và duy trì tình trạng công nhận PTN phù hợp theo ISO/ IEC 17025 [1].

Viện Kiểm nghiệm an toàn vệ sinh thực phẩm Quốc gia (Viện) với vai trò là đơn vị trọng tài cấp quốc gia trong lĩnh vực kiểm nghiệm chất lượng vệ sinh an toàn thực phẩm. Với nhiệm vụ này, Viện đã xây dựng hệ thống chất lượng về TNTT phù hợp với chuẩn mực quốc tế ISO/IEC 17043: 2010 [2] và đã được công nhận bởi tổ chức A2LA-Hoa Kỳ (The American Association for Laboratory Accreditation) [3]. Năm 2017, Viện tiến hành tổ chức 31 chương trình TNTT với 95 chỉ tiêu trên các nền mẫu khác nhau bao gồm lĩnh vực Hóa và Vi sinh đã được 164 phòng thí nghiệm (PTN) tham gia [4].

Bài viết này đưa ra thực trạng tham gia và đánh giá kết quả tham gia TNTT của các PTN đối với lĩnh vực Hóa do Viện tổ chức năm 2017.

\footnotetext{
${ }^{1}$ Điện thoại: 0946631289 Email: danghuucuongvkn@gmail.com
}

40 | Tạp chí KIỂM NGHIẸM VÀ AN TOÀN THỰC PHẨM (Số 2-2018) 


\section{PHƯO'NG PHÁP XỬ LÝ THỐNG KÊ}

Các chương trình TNTT nêu trên được xử lý thống kê theo tiêu chuẩn ISO 17043 và ISO 13528.

* Nhập và xử lý thô

+ Kết quả của các PTN gửi trả được Ban tổ chức nhập vào phần mềm máy tính và có sự kiểm tra rà soát lại bởi 2 người độc lập.

+ Sử dụng các chuẩn thống kê, hàm phân phối chuẩn để loại số lạc trước khi xử lý.

\section{* Các đại lượng đặc trưng}

Các đại lượng đặc trưng được áp dụng theo ISO13528:2015 [5].

Công thức tính các hệ số như sau:

$$
\text { Z-Score [6], [7] }
$$

Hoặc

$$
\mathrm{Z}_{\text {Score }}=\frac{\mathrm{X}-\text { Median }}{\mathrm{IQR}_{\text {Chuẩn }}}
$$

Trong đó:

$$
\mathrm{Z}_{\mathrm{Score}}=\frac{\mathrm{X}-\mathrm{X}^{*}}{\mathrm{~S} *}
$$

+ X là kết quả của phòng thí nghiệm báo cáo.

+ Median là trung vị của kết quả các phòng thí nghiệm báo cáo.

+ IQR và $\mathrm{IQR}_{\mathrm{Chuẩn}}$ là khoảng tứ phân vị và tứ phân vị chuẩn của kết quả các phòng thí nghiệm báo cáo. $\mathrm{IQR}_{\mathrm{Chuẩn}}=0,7413 \times \mathrm{IQR}$.

+ X* là giá trị đồng thuận của các PTN được tính theo thuật toán A ISO 13528:2015.

\section{$>$ Độ không đảm bảo đo của giá trị ấn định}

Hoặc

$$
\mathrm{U}_{\mathrm{x}}=\sqrt{\frac{\pi}{2}} \mathrm{x} \frac{\mathrm{IQR}_{\text {Chuẩn }}}{\sqrt{\mathrm{n}}}
$$

$$
\mathrm{U}_{\mathrm{x}}=\sqrt{\frac{\pi}{2}} \mathrm{x} \frac{\mathrm{S}^{*}}{\sqrt{\mathrm{n}}}
$$

Trong đó:

+ $\mathrm{U}_{\mathrm{X}}$ là độ không đảm bảo đo của giá trị ấn định

$+\mathrm{n}$ là số phòng thí nghiệm tham gia

\section{$>$ Z'-Score}

Trong trường hợp $\mathrm{U}_{\mathrm{X}}>0,3 \mathrm{IQR}_{\mathrm{Chuẩ}}$ hoặc $\mathrm{U}_{\mathrm{X}}>0,3 \mathrm{~S}$ * thì giá trị Z-Score được đánh giá thay bằng giá trị Z'-Score được tính như sau:

$$
\text { Hoặc } \begin{aligned}
Z_{\text {Score }}^{\prime} & =\frac{X-\text { Median }}{\sqrt{\mathrm{IQR}_{\text {Chuẩn }}^{2}+\mathrm{U}_{\mathrm{X}}^{2}}} \\
\mathrm{Z}_{\text {Score }}^{\prime} & =\frac{\mathrm{X}-\mathrm{X}^{*}}{\sqrt{\mathrm{S}^{* 2}+\mathrm{U}_{\mathrm{X}}^{2}}}
\end{aligned}
$$

\section{* Đánh giá kết quả TNTT}

Kết quả TNTT của các PTN được đánh giá thông qua hệ số Z-Score hoặc Z'-Score như sau:

$$
2<\mid \begin{array}{l|l|l|ll}
\text { Z-Score } & \text { hoặc } & \text { Z'-Score } & \leq 2 & \text { : Kết quả đạt yêu cầu } \\
\text { Z-Score } & \text { hoặc } & \text { Z'-Score } & <3 & \text { : Kết quả cảnh báo } \\
\text { Z-Score } & \text { hoặc } & \text { Z'-Score } & \geq 3 & \text { : Kết quả không đạt yêu cầu }
\end{array}
$$


NGHIÊN CÚU KHOA HỌC

Bảng 1. Thông tin các đon vị tham gia chuoong trình TNTT Hóa lý tại Viện năm 2017 [4]

\begin{tabular}{|c|c|c|c|c|c|c|}
\hline TT & Tên chương trình & Chỉ tiêu & Mã số & $\begin{array}{l}\text { Số PTN } \\
\text { tham } \\
\text { gia }\end{array}$ & $\begin{array}{l}\text { Số PTN } \\
\text { trong hệ } \\
\text { thống y tế }\end{array}$ & $\begin{array}{l}\text { Số PTN } \\
\text { được Bộ Y } \\
\text { tế chỉ định }\end{array}$ \\
\hline 1 & TNTT hóa lý trong thực phẩm & $\begin{array}{c}\text { Độ ẩm, Tro, Lipid, } \\
\text { Protein }\end{array}$ & H17.1 & 15 & 7 & 2 \\
\hline 2 & $\begin{array}{l}\text { TNTT hóa lý trong thực phẩm } \\
\text { chức năng }\end{array}$ & $\begin{array}{c}\text { Độ ẩm, Tro, Lipid, } \\
\text { Protein }\end{array}$ & H17.2 & 9 & 5 & 1 \\
\hline 3 & TNTT hóa lý trong cà phê & Độ ẩm; Cafein & H17.4 & 12 & 7 & 3 \\
\hline 4 & TNTT hóa trong nước chấm & $\begin{array}{c}\text { Nitơ tổng, Nitơ } \\
\text { ammoniac, } \mathrm{NaCl} \\
\text { Acid }\end{array}$ & H17.5 & 8 & 5 & 2 \\
\hline 5 & $\begin{array}{l}\text { TNTT vitamin trong thực phẩm } \\
\text { chức năng }\end{array}$ & $\begin{array}{c}\text { Vitamin B1, Vitamin } \\
\text { B2 }\end{array}$ & H17.9 & 13 & 3 & 2 \\
\hline 6 & $\begin{array}{l}\text { TNTT hóa lý trong thực phẩm } \\
\text { chức năng }\end{array}$ & Lysine & H17.15 & 9 & 3 & 3 \\
\hline 7 & TNTT hóa lý trong rượu & $\begin{array}{c}\text { Độ cồn, Methanol, } \\
\text { Ester, Aldehyde, } \\
\text { Furfurol, Rượu bậc } \\
\text { cao }\end{array}$ & H17.16 & 13 & 8 & 4 \\
\hline 8 & TNTT Histamin trong nước mắm & Histamin & H17.24 & 17 & 2 & 4 \\
\hline 9 & $\begin{array}{l}\text { TNTT hóa chất bảo vệ thực } \\
\text { phẩm trong rau quả }\end{array}$ & $\begin{array}{l}\text { Chlorpyrifos, } \\
\text { Permethrin, } \\
\text { Carbofuran }\end{array}$ & H17.28 & 28 & 2 & 6 \\
\hline 10 & TNTT hóa lý trong nước & $\begin{array}{l}\text { Độ cứng, Nitrat, } \\
\text { Nitrit }\end{array}$ & H17.37 & 11 & 7 & 2 \\
\hline 11 & $\begin{array}{l}\text { TNTT kim loại nặng trong nước } \\
\text { giải khát }\end{array}$ & Chì, Cadimi & H17.39 & 47 & 29 & 7 \\
\hline 12 & $\begin{array}{l}\text { TNTT kim loại trong thực phẩm } \\
\text { chức năng }\end{array}$ & Sắt, Kẽm & H17.47 & 11 & 5 & 4 \\
\hline 13 & $\begin{array}{l}\text { TNTT xác định hàm lượng } \\
\text { Curcumin }\end{array}$ & Curcumin & H17.49 & 9 & 2 & 3 \\
\hline 14 & $\begin{array}{l}\text { TNTT định tính Cam thảo, } \\
\text { Đương quy trong Thực phẩm bảo } \\
\text { vệ sức khỏe }\end{array}$ & $\begin{array}{l}\text { Cam thảo, Đương } \\
\text { qui }\end{array}$ & $\mathrm{H} 17.50$ & 32 & 21 & 4 \\
\hline 15 & $\begin{array}{l}\text { TNTT xác định Glucosamine } \\
\text { trong Thực phẩm bảo vệ sức } \\
\text { khỏe }\end{array}$ & Glucosamine & H17.52 & 29 & 17 & 3 \\
\hline 16 & TNTT hóa lý trong Rượu & $\begin{array}{l}\text { Độ cồn, Methanol, } \\
\text { Ester, Aldehyde, } \\
\text { Furfurol, Rượu bậc } \\
\text { cao }\end{array}$ & H17.81 & 51 & 49 & 3 \\
\hline
\end{tabular}




\begin{tabular}{|c|l|c|c|c|c|c|}
\hline 17 & TNTT Aflatoxin trong bột ngô & $\begin{array}{c}\text { Aflatoxin B1, B2, } \\
\text { G1, G2 }\end{array}$ & H17.82 & 22 & 5 & 6 \\
\hline 18 & $\begin{array}{l}\text { TNTT hóa lý và vitamin trong } \\
\text { thực phẩm bảo vệ sức khỏe }\end{array}$ & $\begin{array}{c}\text { Độ ẩm, Tro, Protein, } \\
\text { Lipid, Vitamin A, } \\
\text { Vitamin E }\end{array}$ & H17.83 & 64 & 37 & 7 \\
\hline 19 & $\begin{array}{l}\text { TNTT kim loại trong thực phẩm } \\
\text { bảo vệ sức khỏe }\end{array}$ & Canxi, Sắt & H17.84 & 34 & 14 & 4 \\
\hline
\end{tabular}

III. KẾT QUẢ

\section{THỬC TRẠG THAM GIA TNTT CỦA CÁC PTN VỀ CHỈ TIÊU HÓA LÝ NĂM 2017}

Năm 2017, Viện đã tổ chức nhiều chương trình hóa lý được 155 PTN tham gia, trong đó có 94 đơn vị thuộc hệ thống y tế và 23 đơn vị được Bộ Y tế chỉ định là đơn vị kiểm nghiệm phục vụ quản lý nhà nước theo Thông tư liên tịch số 20/2013/TTLT-BYT-BCT-BNNPTNT nêu trong bảng 1.

Từ các số liệu thống kê ở bảng 1 , đồ thị biểu diễn các đơn vị tham gia TNTT lĩnh vực Hóa năm 2017 được thể hiện trong hình 1.

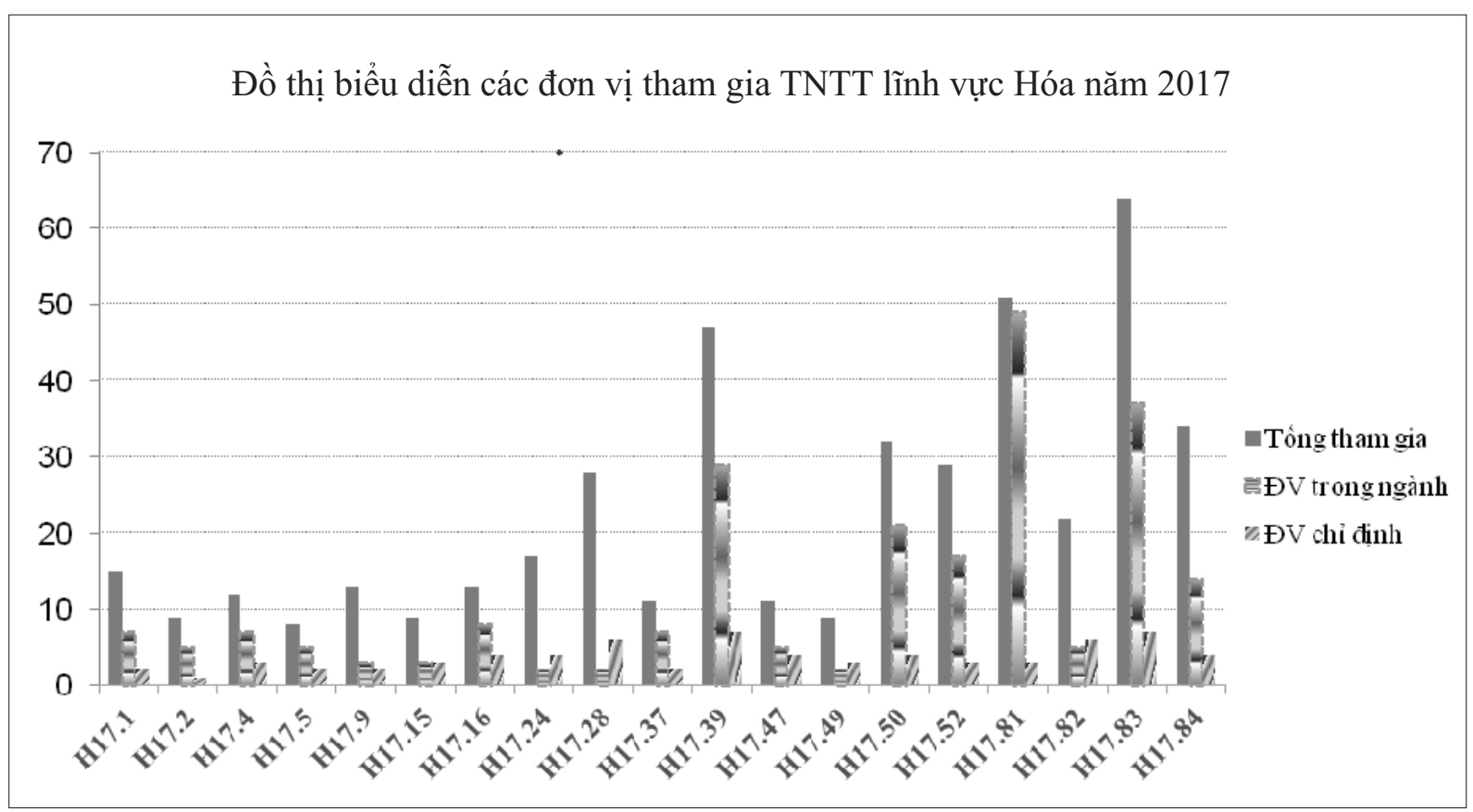

Hình 1. Đồ thị biểu diễn các đơn vị tham TNTT trong lĩnh vực Hóa năm 2017

Kết quả từ đồ thị hình 1 cho thấy, số PTN trong ngành Y tế (Trung tâm y tế dự phòng, Trung tâm kiểm nghiệm, các Viện khu vực) tham gia TNTT còn hạn chế, đặc biệt là những chương trình thu phí. Một số các chương trình miễn phí thì các PTN có tham gia nhiều hơn như TNTT hóa lý và vitamin trong thực phẩm bảo vệ sức khỏe, TNTT hóa lý trong Rượu, TNTT kim loại nặng trong nước giải khát, tuy nhiên tính cả chương trình thu phí và miễn phí thì số các PTN trong hệ thống quản lý của BYT tham gia là ít so với số các đơn vị trong 63 tỉnh thành, chương trình tham gia nhiều nhất là 49 đơn vị/ 63 tỉnh thành.

\section{2. ĐÁNH GIÁ KẾT QUẢ TNTT CỦA CÁC PTN ĐỐI VỚI CHİ TIÊU HÓA LÝ}

Đối với lĩnh vực Hóa lý trong năm 2017, Viện đã tổ chức 19 chương trình TNTT được chia làm 3 đợt với 54 chỉ tiêu trên các nền mẫu như thực phẩm, thực phẩm chức năng, nước... được tổng hợp trong bảng 2 . 
Bảng 2. Số liệu đánh giá kết quả TNTT của các PTN

\begin{tabular}{|c|c|c|c|c|c|c|c|c|c|c|c|c|c|c|}
\hline \multirow{2}{*}{\multicolumn{2}{|c|}{ SỐ LIẸU NĂM 2017 }} & \multirow{3}{*}{$\begin{array}{c}P T N \\
\text { tham } \\
\text { gia } \\
14\end{array}$} & \multirow{3}{*}{$\begin{array}{l}\text { Báo } \\
\text { hùy }\end{array}$} & \multicolumn{3}{|c|}{ Kết quả đánh giá (\%) } & \multirow{3}{*}{$\begin{array}{c}\text { PTN } \\
\text { trong } \\
\text { ngành } \\
\text { y tế }\end{array}$} & \multicolumn{3}{|c|}{$\begin{array}{l}\text { Kết quả đánh giá (\% so } \\
\text { với tổng số tham gia) }\end{array}$} & \multirow{3}{*}{$\begin{array}{c}\text { PTN } \\
\text { durợc } \\
\text { chi } \\
\text { dịnh } \\
4\end{array}$} & \multicolumn{3}{|c|}{$\begin{array}{l}\text { Kết quả đánh giá (\% so } \\
\text { vói tổng sồ tham gia) }\end{array}$} \\
\hline & & & & \multirow{2}{*}{$\begin{array}{c}Ð a t \\
78,6\end{array}$} & \multirow{2}{*}{$\begin{array}{c}\text { Cảnh } \\
\text { báo } \\
-\end{array}$} & \multirow{2}{*}{$\begin{array}{l}K \oslash \\
21,4\end{array}$} & & \multirow{2}{*}{$\begin{array}{l}\text { Đạt } \\
83,3\end{array}$} & \multirow{2}{*}{$\begin{array}{c}\text { Cảnh } \\
\text { Báo } \\
-\end{array}$} & \multirow{2}{*}{$\begin{array}{l}K \oslash \\
16,7\end{array}$} & & \multirow{2}{*}{$\begin{array}{c}\text { Đat } \\
100,0\end{array}$} & \multirow{2}{*}{$\begin{array}{l}\text { Cảnh } \\
\text { Báo } \\
-\end{array}$} & \multirow{2}{*}{$\begin{array}{c}K \oplus \\
-\end{array}$} \\
\hline \multirow{4}{*}{ H17.1 } & Protein & & & & & & & & & & & & & \\
\hline & Lipid & 14 & & 100,0 & - & - & 6 & 100,0 & - & - & 4 & 100,0 & - & - \\
\hline & Tro & 13 & & 100,0 & - & - & 6 & 100,0 & - & - & 4 & 100,0 & - & - \\
\hline & Độ ẩm & 15 & & 100,0 & - & - & 7 & 100,0 & - & - & 4 & 100,0 & - & - \\
\hline \multirow{4}{*}{ H17.2 } & Protein & 6 & & 100,0 & - & - & 4 & 100,0 & - & - & 2 & 100,0 & - & - \\
\hline & Lipid & 6 & & 83,3 & 16,7 & - & 3 & 100,0 & - & - & 3 & 100,0 & - & - \\
\hline & Tro & 8 & & 100,0 & - & - & 4 & 100,0 & - & - & 3 & 100,0 & - & \\
\hline & Độ ẩm & 8 & & 62,5 & 12,5 & 25,0 & 4 & 50,0 & 25,0 & 25,0 & 3 & 100,0 & - & \\
\hline \multirow[b]{2}{*}{ H17.4 } & Caffein & 12 & & 75,0 & - & 25,0 & 7 & 71,4 & - & 28,6 & 4 & 50,0 & - & 50,0 \\
\hline & Độ ẩm & 11 & & 100,0 & - & - & 6 & 100,0 & - & - & 4 & 100,0 & - & - \\
\hline \multirow{4}{*}{ H17.5 } & Nitơ tổng & 8 & & 75,0 & - & 25,0 & 5 & 60,0 & - & 40,0 & 4 & 75,0 & - & 25,0 \\
\hline & Nito amoniac & 6 & & 66,7 & 16,7 & 16,7 & 3 & 66,7 & - & 33,3 & 3 & 66,7 & 33,3 & - \\
\hline & Muối & 7 & & 85,7 & - & 14,3 & 4 & 75,0 & - & 25,0 & 4 & 75,0 & - & 25,0 \\
\hline & Acid & 8 & & 87,5 & - & 12,5 & 5 & 80,0 & - & 20,0 & 4 & 100,0 & - & \\
\hline \multirow{2}{*}{ H17.9 } & B1 & 13 & & 76,9 & 15,4 & 7,7 & 3 & 66,7 & 33,3 & - & 2 & 100,0 & - & \\
\hline & B2 & 12 & & 66,7 & - & 33,3 & 3 & 66,7 & - & 33,3 & 1 & 100,0 & - & \\
\hline H17.15 & Lysine & 9 & & 77,8 & 11,1 & 11,1 & 3 & 100,0 & - & - & 3 & 100,0 & - & \\
\hline \multirow{6}{*}{ H17.16 } & Ethanol & 13 & & 92,3 & 7,7 & - & 8 & 100,0 & - & - & 6 & 83,3 & 16,7 & - \\
\hline & Methanol & 10 & & 80,0 & 10,0 & 10,0 & 7 & 71,4 & 14,3 & 14,3 & 5 & 80,0 & - & 20,0 \\
\hline & Ester & 9 & & 77,8 & 22,2 & - & 6 & 66,7 & 33,3 & - & 5 & 80,0 & 20,0 & - \\
\hline & Aldehyde & 10 & & 70,0 & - & 30,0 & 7 & 57,1 & - & 42,9 & 5 & 80,0 & - & 20,0 \\
\hline & Furfurol & 9 & & 77,8 & - & 22,2 & 6 & 66,7 & - & 33,3 & 5 & 80,0 & - & 20,0 \\
\hline & Rượu BC & 7 & & 57,1 & - & 42,9 & 4 & 50,0 & - & 50,0 & 5 & 60,0 & - & 40,0 \\
\hline H17.24 & Histamin & 20 & 3 & 70,6 & 11,8 & 17,6 & 2 & 100,0 & - & - & 8 & 71,4 & - & 28,6 \\
\hline
\end{tabular}


NGHIÊN CÚU KHOA HỌC

\begin{tabular}{|c|c|c|c|c|c|c|c|c|c|c|c|c|c|c|}
\hline \multirow{3}{*}{ H17.28 } & Chlorpyrifos & 28 & 1 & 77,8 & - & 22,2 & 2 & 100,0 & - & - & 9 & 87,5 & - & 12,5 \\
\hline & Permethrin & 27 & 1 & 73,1 & 23,1 & 3,8 & 2 & 100,0 & - & - & 9 & 87,5 & 12,5 & - \\
\hline & Carbofuran & 26 & 1 & 84,0 & 4,0 & 12,0 & 2 & 100,0 & - & - & 8 & 85,7 & 14,3 & - \\
\hline \multirow{3}{*}{ H17.37 } & Độ cứng & 11 & & 81,8 & 9,1 & 9,1 & 7 & 71,4 & 14,3 & 14,3 & 3 & 100,0 & - & - \\
\hline & Nitrat & 11 & & 90,9 & 9,1 & - & 7 & 85,7 & 14,3 & - & 3 & 100,0 & - & - \\
\hline & Nitrit & 11 & & 72,7 & 18,2 & 9,1 & 7 & 100,0 & - & - & 3 & 66,7 & 33,3 & - \\
\hline \multirow{2}{*}{ H17.39 } & $\mathrm{Pb}$ & 51 & 4 & 78,7 & 8,5 & 12,8 & 31 & 75,9 & 10,3 & 13,8 & 12 & 91,7 & - & 8,3 \\
\hline & $\mathrm{Cd}$ & 50 & 4 & 91,3 & 2,2 & 6,5 & 30 & 85,7 & 3,6 & 10,7 & 12 & 91,7 & - & 8,3 \\
\hline \multirow{2}{*}{ H17.47 } & $\mathrm{Fe}$ & 11 & & 81,8 & 9,1 & 9,1 & 2 & 100,0 & - & - & 3 & 100,0 & - & - \\
\hline & $\mathrm{Zn}$ & 11 & & 81,8 & - & 18,2 & 5 & 100,0 & - & - & 4 & 100,0 & - & - \\
\hline H17.49 & Curcumin & 9 & & 100,0 & - & - & 5 & 80,0 & - & 20,0 & 4 & 100,0 & - & - \\
\hline \multirow{2}{*}{ H17.50 } & Cam thảo & 32 & & 100,0 & - & - & 21 & 100,0 & - & - & 5 & 100,0 & - & - \\
\hline & Đương qui & 32 & & 90,6 & - & 9,4 & 21 & 90,5 & - & 9,5 & 5 & 100,0 & - & - \\
\hline H17.52 & Glucosamine & 31 & 2 & 82,8 & 3,4 & 13,8 & 19 & 82,4 & 5,9 & 11,8 & 4 & 100,0 & - & - \\
\hline \multirow{6}{*}{ H17.81 } & Ethanol & 52 & 3 & 87,8 & 4,1 & 8,2 & 51 & 87,5 & 4,2 & 8,3 & 8 & 85,7 & - & 14,3 \\
\hline & Methanol & 45 & 3 & 57,1 & 23,8 & 19,0 & 44 & 56,1 & 24,4 & 19,5 & 7 & 66,7 & 16,7 & 16,7 \\
\hline & Ester & 20 & 3 & 100,0 & - & - & 19 & 100,0 & - & - & 6 & 100,0 & - & - \\
\hline & Aldehyde & 42 & 3 & 89,7 & 5,1 & 5,1 & 41 & 89,5 & 5,3 & 5,3 & 7 & 100,0 & - & - \\
\hline & Furfurol & 28 & 3 & 84,0 & 12,0 & 4,0 & 26 & 82,6 & 13,0 & 4,3 & 6 & 80,0 & 20,0 & - \\
\hline & Rượu BC & 12 & 3 & 66,7 & - & 33,3 & 11 & 62,5 & - & 37,5 & 5 & 100,0 & - & - \\
\hline \multirow{4}{*}{ H17.82 } & Aflatoxin B1 & 25 & 3 & 86,4 & 9,1 & 4,5 & 6 & 100,0 & - & - & 10 & 88,9 & 11,1 & - \\
\hline & Aflatoxin B2 & 22 & 3 & 84,2 & 5,3 & 10,5 & 5 & 100,0 & - & - & 9 & 87,5 & 12,5 & - \\
\hline & Aflatoxin G1 & 23 & 3 & 60,0 & 15,0 & 25,0 & 5 & 75,0 & - & 25,0 & 9 & 50,0 & 12,5 & 37,5 \\
\hline & Aflatoxin G2 & 23 & 3 & 90,0 & - & 10,0 & 5 & 100,0 & - & - & 9 & 100,0 & - & - \\
\hline \multirow{6}{*}{ H17.83 } & Protein & 47 & 2 & 93,3 & - & 6,7 & 26 & 92,0 & - & 8,0 & 11 & 100,0 & - & - \\
\hline & Lipid & 47 & 2 & 64,4 & 6,7 & 28,9 & 25 & 54,2 & 4,2 & 41,7 & 12 & 75,0 & - & 25,0 \\
\hline & Tro & 58 & 2 & 83,9 & 7,1 & 8,9 & 34 & 84,8 & 6,1 & 9,1 & 12 & 83,3 & 8,3 & 8,3 \\
\hline & Độ ẩm & 63 & 2 & 88,5 & 9,8 & 1,6 & 38 & 86,5 & 10,8 & 2,7 & 12 & 100,0 & - & - \\
\hline & VTM_A & 25 & 2 & 87,0 & 4,3 & 8,7 & 9 & 87,5 & 12,5 & - & 9 & 100,0 & - & - \\
\hline & VTM_E & 24 & 2 & 77,3 & 9,1 & 13,6 & 8 & 71,4 & - & 28,6 & 8 & 100,0 & - & - \\
\hline \multirow{2}{*}{ H17.84 } & $\mathrm{Ca}$ & 32 & 3 & 79,3 & - & 20,7 & 12 & 80,0 & - & 20,0 & 10 & 70,0 & - & 30,0 \\
\hline & $\mathrm{Fe}$ & 37 & 3 & 76,5 & 5,9 & 17,6 & 16 & 57,1 & 14,3 & 28,6 & 10 & 90,0 & - & 10,0 \\
\hline
\end{tabular}




\section{Đồ thị biểu diễn kết quả tham gia của các PTN}

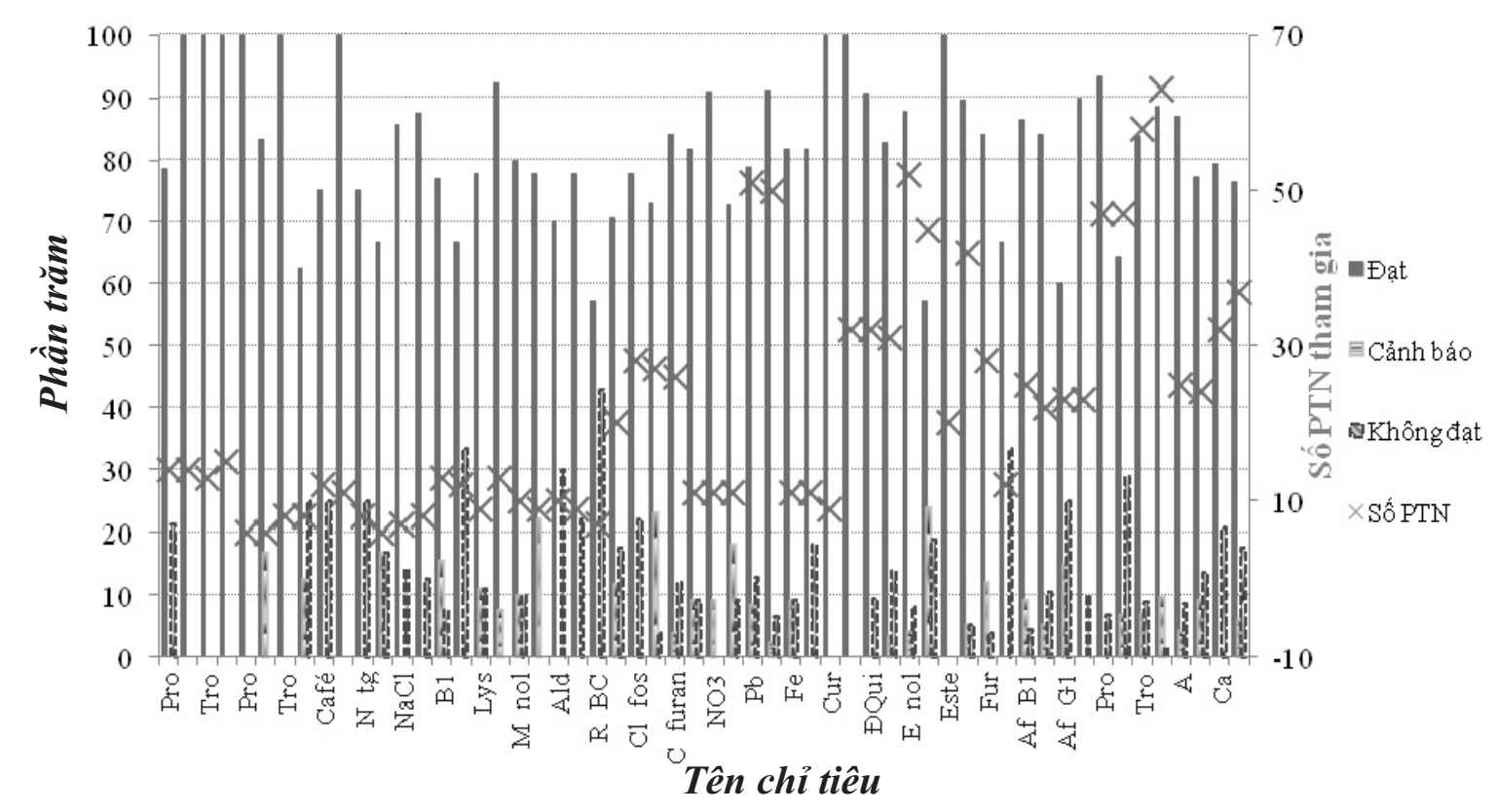

Hình 2. Đồ thị biểu diễn kết quả TNTT của các PTN

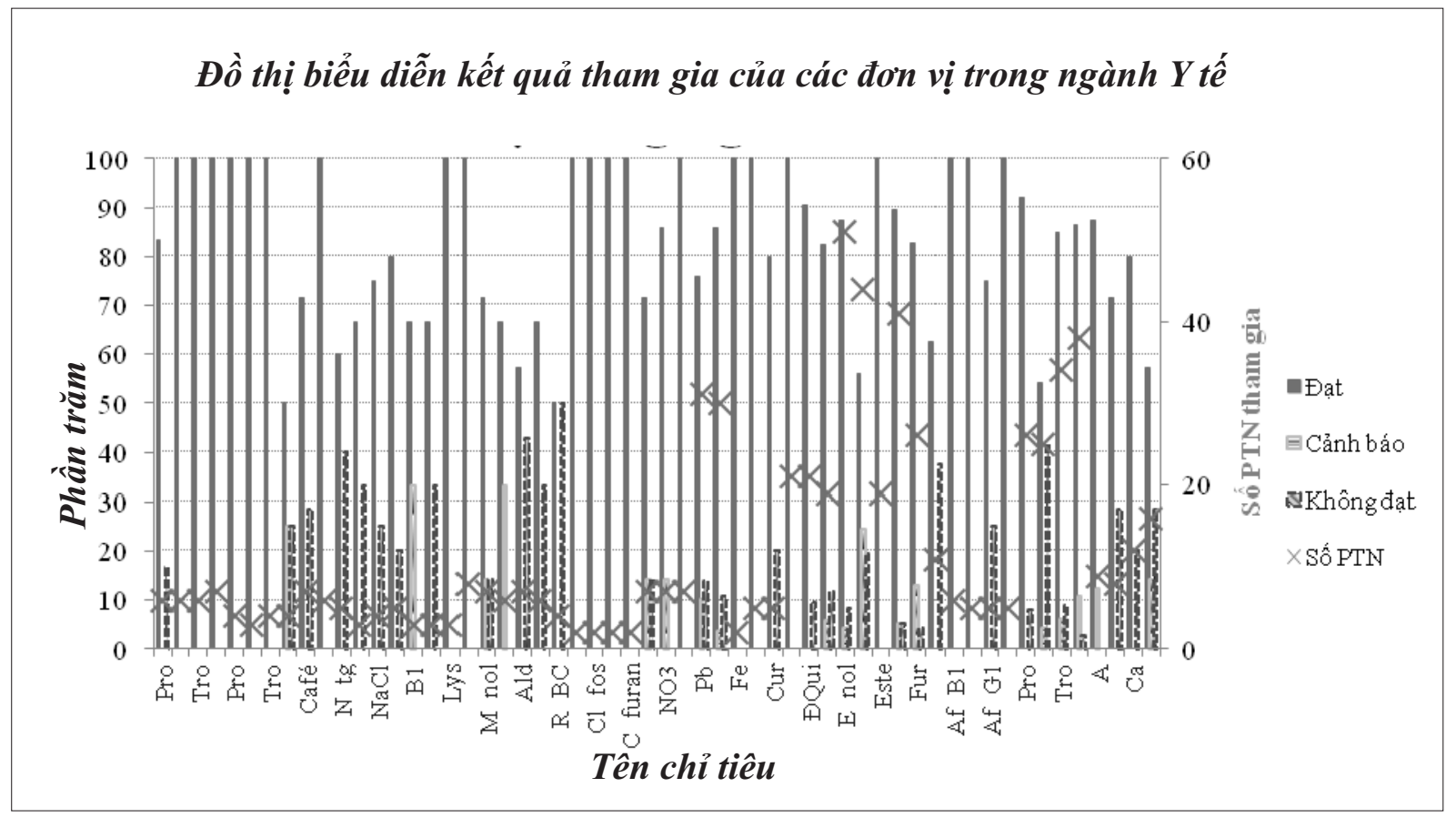

Hình 3. Đồ thị biểu diễn kết quả TNTT của các PTN trong ngành Y tế

Trên cơ sở các số liệu ở bảng 2, các đồ thị biểu diễn đánh giá kết quả TNTT lĩnh vực Hóa lý năm 2017 của các PTN, của các đơn vị trong ngành Y tế và các đơn vị được Bộ Y tế chỉ định được thể hiện tương ứng trong hình 2 , hình 3 và hình 4 .

Từ Đồ thị hình 2 cho thấy kết quả "đạt yêu cầu" của các phòng thử nghiệm đa số nằm ở một số 46 | Tạp chí KIỂM NGHIỆM VÀ AN TOÀN THỰC PHẨM (Số 2-2018) 


\section{Đồ thị biểu diễn kết quả tham gia của các đơn vị được Bộ Y tế chỉ định}

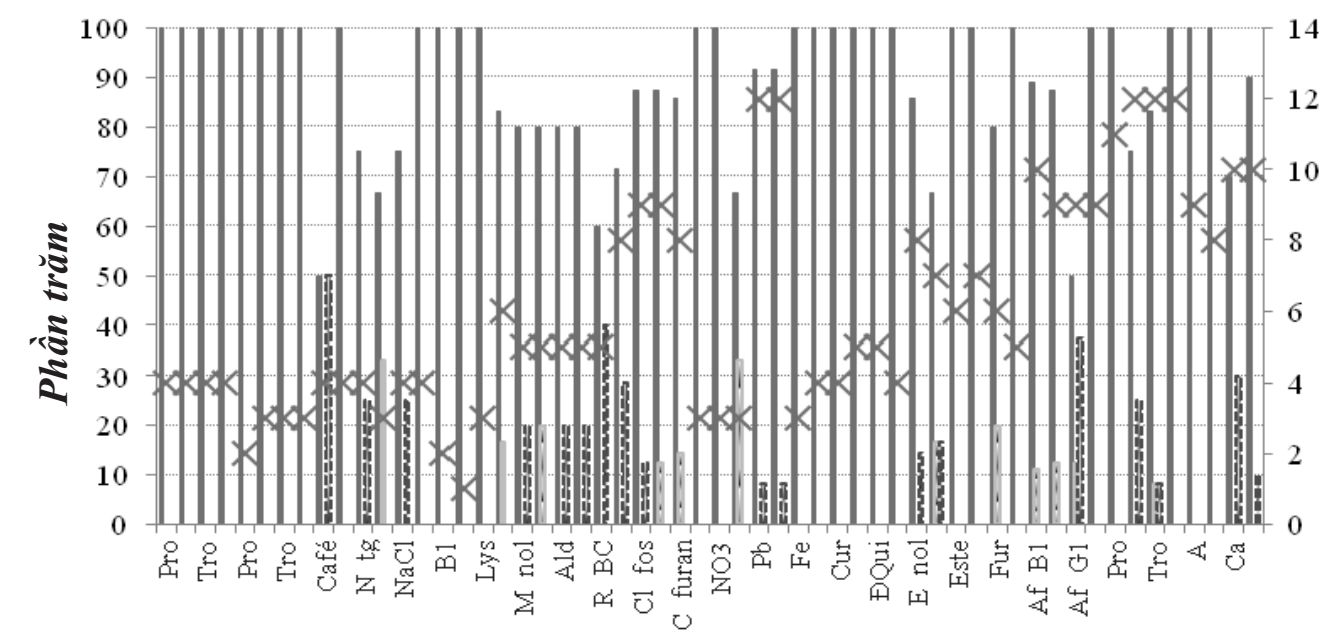

Tên chỉ tiêu

Hình 4. Đồ thị biểu diễn kết quả TNTT của các PTN được Bộ Y tế chỉ định

chỉ tiêu đơn giản như độ ẩm, tro, Protein, lipid trong thực phẩm, thực phẩm chức năng, hoặc chỉ tiêu về hàm lượng muối, hàm lượng acid trong nước mắm, hàm lượng ethanol, este, aldehyd, furfurol trong rượu... Các chỉ tiêu khó cần phân tích trên hệ thống sắc ký, quang phổ thì tỷ lệ "đạt yêu cầu" nhìn chung là không cao. Tuy nhiên, các phòng thử nghiệm được Bộ Y tế chỉ định thì tỷ lệ "đạt yêu cầu" là rất cao, bao gồm cả chỉ tiêu đơn giản và phức tạp. Kết quả này cho thấy năng lực của các phòng được chỉ định là rất tốt, các đơn vị này có đủ về năng lực kỹ thuật để đáp ứng với hầu hết các chỉ tiêu phân tích trên thiết bị hiện đại có độ chính xác cao.

Theo đồ thị hình 3 cho thấy các PTN trong ngành Y tế đã tham gia thì kết quả "đạt yêu cầu" đối với các chỉ tiêu khá cao. Tuy nhiên, một số chỉ tiêu năng lực kiểm nghiệm của các đơn vị cũng cần phải xem xét như chỉ tiêu Rượu bậc cao, Aldehyde của chương trình H17.16; đặc biệt là độ ẩm của chương trình H17.2; lipid của chương trình H17.83, Methanol của chương trình H17.81,..

Từ đồ thị hình 4 có thể nhận thấy năng lực kiểm nghiệm các đơn vị được Bộ Y tế chỉ định là đơn vị kiểm nghiệm phục vụ quản lý Nhà Nước tương đối đồng đều, thể hiện phần trăm "Đạt yêu cầu" thử nghiệm thành thạo rất cao so với tổng số PTN tham gia.

\section{BÀN LUẬN VÀ NHẬN XÉT}

* Thông qua số liệu thử nghiệm thành thạo, năm 2017 tại Viện Kiểm nghiệm an toàn vệ sinh thực phẩm Quốc gia cho thấy phần nào bức tranh tổng thể năng lực kiểm nghiệm về lĩnh vực Hóa lý đối với các phòng kiểm nghiệm thực phẩm hiện tại trong nước, đặc biệt các phòng thử nghiệm hiện nay đã gia tăng cả về số lượng và chất lượng.

* Thông qua kết quả thử nghiệm thành thạo, các đơn vị có thể tự đánh giá năng lực thực tế của mình để từ đó có các biện pháp phòng ngừa và cải tiến để nâng cao năng lực kiểm nghiệm.

* Qua kết quả thử nghiệm thành thạo, các phòng thử nghiệm không đạt hoặc cảnh báo cần tìm ra các nguyên nhân gây ảnh hưởng đến kết quả phân tích để khắc phục như: Các hóa chất, dung môi phải tinh khiết và còn hạn sử dụng; thiết bị cần phải hiệu chuẩn, bảo dưỡng định kỳ theo quy định, 
tay nghề nhân viên cần được kiểm tra và đánh giá thường xuyên, môi trường và điều kiện phân tích cần đáp ứng tốt để thích hợp với yêu cầu của mỗi phép phân tích.

* Bài viết này có thể phần nào giúp các cơ quan quản lý nhà nước về kiểm nghiệm thực phẩm nhìn nhận được thực trạng năng lực kiểm nghiệm của các đơn vị đã được chỉ định phục vụ quản lý nhà nước về kiểm nghiệm an toàn thực phẩm để từ đó có những định hướng tiếp theo trong vấn đề kiểm nghiệm thực phẩm nói riêng và quản lý an toàn thực phẩm nói chung trên phạm vi cả nước.

* Thông qua báo cáo, các đơn vị, tổ chức, doanh nghiệp... có thể nhìn nhận được để từ đó lựa chọn cho mình một đơn vị kiểm nghiệm thực phẩm có năng lực nhằm đảm bảo kết quả kiểm nghiệm một cách tốt nhất.

\section{TÀI LIỆU THAM KHẢO VÀ NGUỒN SỐ LIẸU}

1. ISO/IEC 17025:2005 General requirements for the competence of testing and calibration laboratories.

2. ISO/IEC 17043:2010 Conformity assessment - General requirements for proficiency testing.

3. Yêu cầu và chính sách của tổ chức A2LA - Hoa Kỳ (The American Association for Laboratory Accreditation) đối với chứng chỉ số: 4254.01 ngày 15/5/2017 cấp cho Viện Kiểm nghiệm an toàn vệ sinh thực phẩm Quốc gia.

4. Báo cáo kết quả thử nghiệm thành thạo của Viện Kiểm nghiệm an toàn vệ sinh thực phẩm Quốc gia năm 2017.

5. ISO/IEC 13528:2015 Statistical methods for use in proficiency testing by interlaboratory comparisons (second edition 2015-08-01, corrected version 2016-10-15)

6. P.TT.05 - Thủ tục phân tích dữ liệu và đánh giá kết quả chương trình TNTT của Viện Kiểm nghiệm an toàn vệ sinh thực phẩm Quốc gia.

7. P.HD.02 - Hướng dẫn tính giá trị ấn định và phương pháp phân tích của Viện Kiểm nghiệm an toàn vệ sinh thực phẩm Quốc gia.

8. P.ST - Sổ tay chất lượng thử nghiệm thành thạo của Viện Kiểm nghiệm an toàn vệ sinh thực phẩm Quốc gia.

9. Danh sách các đơn vị được Bộ Y tế chỉ định theo Thông tư liên tịch số 20/2013/TTLT-BYTBCT-BNNPTNN.

\section{Summary}

CHEMISTRY PROFICIENCY TESTING PROGRAMS AT NATIONAL INSTITUTE FOR FOOD CONTROL (NIFC) IN THE YEAR 2017

\section{Dang Huu Cuong}

National Institute for Food Control

Proficiency testing plays a very important role in ensuring the quality of testing. Based on the results of the proficiency testing, the managers as well as the relevant members could assess the technical competence of the laboratory. Participating in proficiency testing is an evidence that a laboratory is implementing a quality management program in accordance with ISO/IEC 17025. Through the proficiency testing program, the participating laboratories themselves could evaluate their capabilities and address the causes affecting the quality of tests so as to take measures to ensure better quality assurance. This study provides a snapshot of the testing capacity of food testing laboratories within and outside the health sector based on chemistry proficiency testing conducted by the National Institute for Food Control (NIFC) in 2017.

Keywords: Proficiency testing, Proficiency testing results, food testing, National Institute for Food Control (NIFC) 